\title{
Examples of adverse effects after biological therapy
}

\author{
Ewa Hadas, Andrzej Bozek, Anna Cudak, Aleksandra Ciuk, Jerzy Jarząb \\ Clinical Department of Internal Disease, Dermatology and Allergology in Zabrze, Medical University of Silesia in Katowice, Poland \\ Adv Dermatol Allergol 2020; XXXVII (5): 712-718 \\ DOI: https://doi.org/10.5114/ada.2020.100482
}

\begin{abstract}
Psoriasis is one of the most common, chronic skin diseases of as yet unexplained etiopathogenesis. In the recent years it has been proven that an immunological factor plays an important role in the dermatosis onset. This has led to introduction of biological drugs to the disease treatment regimen, which include, inter alia, adalimumab and ustekinumab. New therapy has become an alternative for patients with psoriasis resistant to standard treatment methods as well as an alternative form of treatment in case of occurrence of severe adverse drug reactions after administration of standard treatment. Despite good treatment results the administration of these drugs is associated with the occurrence of adverse reactions. This article presents cases of 4 patients who have been administered biological treatment and in whom there have been observed, inter alia, the occurrence of hypersensitivity reactions in the form of acute urticaria as well as skin lesions of erythema multiforme nature or positive antinuclear antibodies titre. The symptoms experienced by the presented patients posed no direct threat to life and the benefits of the drugs' administration had a significant therapeutic importance.
\end{abstract}

Key words: biological therapy, psoriasis, adalimumab, ustekinumab, adverse effects.

\section{Introduction}

Psoriasis is one of the most frequent, chronic inflammatory skin diseases of complex pathogenesis. The course of the disease is influenced by genetic factors and environmental conditions. It is estimated that $2-4.8 \%$ of the population is affected by the disease and it has similar occurrence frequency in both males and females. Skin lesions are caused by interaction of genetic, immunologic and environmental factors [1].

Currently, it is believed that excessive epidermal proliferation in psoriasis is a result of immunological disorders associated with T-lymphocyte activity and the cytokines released by them: tumour necrosis factor $\alpha$ (TNF- $\alpha$ ) and interleukins - IL-12, II-17, IL-23. Both Th1 lymphocyte activation and cytokine production lead to excessive keratinocyte proliferation as well as induction and support of inflammatory condition [2, 3]. Additionally, patients with psoriasis are exposed to more frequent occurrence of ischemic heart disease, obesity, diabetes and depression [4]. In particular this occurs when the disease affects extensive body areas. In some cases psoriasis may affect family lives and lead to occurrence of other serious problems such as social exclusion [5]. Various types of questionnaires (e.g. SF-36, DLQI, PDI) are used in clini- cal practice to determine the patient's quality of life. It has been demonstrated that the influence of psoriasis on patient's general feeling is comparable to the state observed in severe chronic diseases such as neoplasms, arthritis or depression [6].

Many patients with psoriasis require administration of general and complex treatment which is frequently associated with high costs and the risk of adverse reactions. For patients with moderate and severe psoriasis, who have not demonstrated any effects after traditional treatment, administration of biological drugs which positively affect immunological processes by blocking the activity of selected cytokines directly interfering with a cascade of the phenomena occurring in the inflammatory state is the effective treatment method. Introduction of biological drugs has revolutionized treatment of moderate and severe psoriasis and psoriatic arthritis. Biological drugs used in treatment of psoriasis and psoriatic arthritis include, inter alia:

- TNF- $\alpha$ inhibitors - adalimumab, etanercept, infliximab, - IL-12 and IL-23 inhibitors - ustekinumab,

- IL-17A inhibitors - secukinumab, ixekizumab,

- medicinal agents inhibiting T lymphocyte proliferation, - alefacept,

Address for correspondence: Ewa Hadas MD, PhD, Clinical Department of Internal Disease, Dermatology and Allergology, Medical University of Silesia, 10 Skłodowskiej St, 41-800 Zabrze, Poland, phone: +48 32271 31 65, e-mail: ewahadas@interia.pl Received: 16.02.2018, accepted: 6.03.2019. 
- LFA-1 subunit adhesive particle blockers - efalizumab and other medicinal agents at various stages of clinical trials or the registration process.

In Poland, for 5 years there have been drug programs, within which patients are qualified to be administered free treatment with biological drugs. One of such drug programs includes plague-like psoriasis treatment and the other one, the treatment of arthropathic psoriasis. Patients who demonstrated no improvement after prior administration of at least two methods of classical general treatment are included in both drug programs. Due to an increasing number of patients being administered the above-mentioned drugs, an increasing number of adverse reactions after the drug administration have been recorded.

\section{Aim}

The paper aims to present the adverse reactions which occurred during administration of biological drugs, in particular during administration of adalimumab and ustekinumab, on the basis of my own observations. The described adverse reactions were observed in patients treated in the Clinical Department of Internal Diseases, Dermatology and Allergology Specialist Hospital in Zabrze in 2011-2016. The characteristics of the patients were presented in Table 1.

\section{Description of cases}

Among the analysed cases of patients taking biological drugs the occurrence of various skin lesions as a treatment-related adverse reaction was observed. There were also observed hematologic disorders and deterioration of the general health condition.

In November 2013, adalimumab (Humira) therapy was started in a 46-year-old patient, who has been suffering from psoriasis vulgaris since 1989. A dissemination of maculopapular rash on the trunk and upper extremities with concurrent pruritus (Figures 1 A, B) was observed after 3 months of treatment. The patient was given antihistamines, including antazoline (Phenazolinum), and was given a clobetasol ointment (Novate) locally, i.e. on skin surface. Adalimumab administration was discontinued. After 2 weeks papular symptoms subsided, with pruritus symptoms still being persistent and producing numerous skin excoriations and erosions. In the performed laboratory tests, eosinophilia (21.4\%) and elevated alanine aminotransferase levels (91 IU/l) were recorded. In the eosinophilia diagnostic procedure, parasitic diseases and hematologic causes were excluded. According to a haematologist's recommendations, the adalimumab treatment was continued with simultaneous administration of triamcinolone in the initial dose of $8 \mathrm{mg} /$ day for 7 days and then in the dose of $4 \mathrm{mg} /$ day. Laboratory tests performed 10 days after administration of the drug demonstrated a decrease in the eosinophilic granulocyte level to $6.3 \%$ and after 2 weeks to $4.2 \%$, achieving complete normalization after 2 months. Due to the drug program requirements, adalimumab administration was discontinued after 48 weeks of treatment. Triamcinolone $4 \mathrm{mg}$ was administered until the therapy completion as prior attempts at the drug discontinuation led to pruritus recurrence.

After 9 months from treatment completion, intensification of pathological lesions in the course of psoriasis allowed to re-include the patient's to the drug program. The patient yet again was administered adalimumab, initially with good tolerance and clinical effect. However, after 3 months of treatment there occurred dissemination of erythema exudativum lesions resembling bull's eye targets, localized in groins and ulnar flexions. A centrally localized vesicle appeared in some of the lesions. Additionally, the patient experienced a strong burning sensation and pruritus. Adalimumab treatment was discontinued and intensive dexamethasone $8 \mathrm{mg}$ oral treatment was initiated, followed by oral administration of methylprednisolone $16 \mathrm{mg}$ and antazoline in $2 \times 1$ ampoule. After 2 weeks there was observed a significant improvement of the patient's clinical condition, pallor of skin lesions and their circumferential exfoliation. After 6 weeks the lesions subsided completely and it was decided to continue adalimumab treatment.

In July 2014, adalimumab 40 mg (Humira) treatment, with the drug being administered subcutaneously two times per month was started in another 23-year-old female patient suffering from psoriasis vulgaris and diagnosed with psoriatic arthritis. A reduction of skin lesions (PASI score 75\%) and regression of articular complaints were achieved. After 4 months of treatment (December 2014), a few hours after adalimumab injection an inflammatory infiltration appeared in the drug injection site, i.e. on the surface of the abdominal skin (Figure 2). In

Table 1. Characteristics of patients before therapy

\begin{tabular}{lc}
\hline Parameter & Result \\
\hline Age, mean [years] & 61.6 \\
\hline Men & 30 \\
\hline Women & 20 \\
\hline Duration of disease before therapy - mean [years] & 17.6 \\
\hline PASI score before therapy, mean & 22.9 \\
\hline DLQI score before therapy, mean & 22 \\
\hline Percentage of affected skin surface acc. BSA before & 45 \\
\hline therapy, mean & \\
\hline Number of patients using: & 40 \\
\hline Adalimumab & 10 \\
\hline Number of patients using ustekinumab & \\
\hline
\end{tabular}

PASI - Psoriasis Area and Severity Index, DLQI - Dermatology Life Quality Index, BSA - body surface area. 

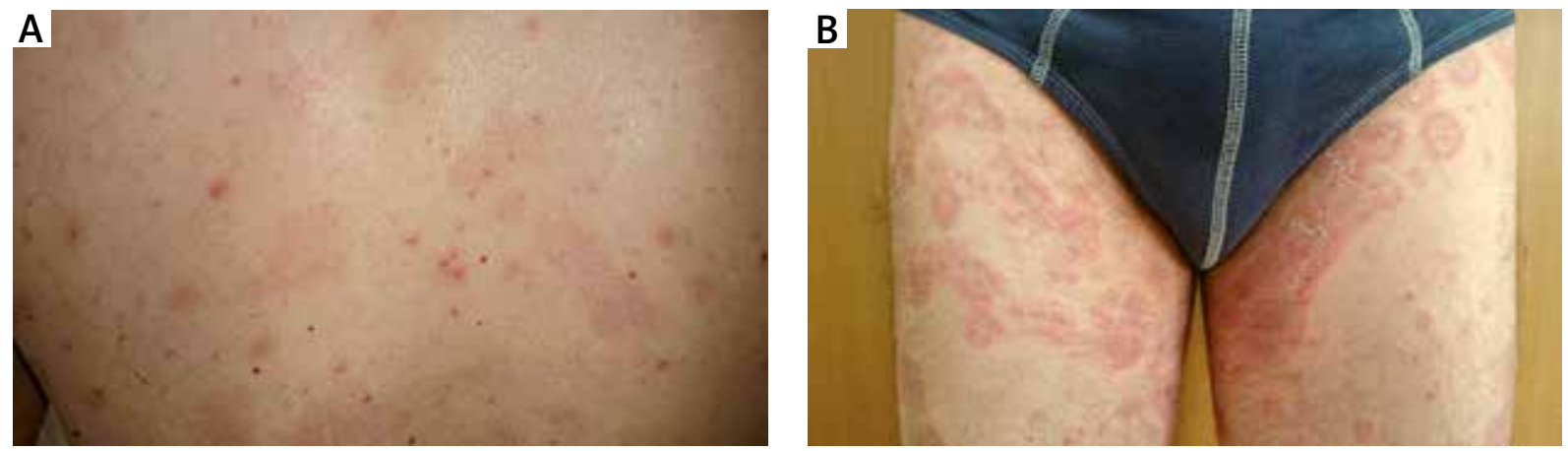

Figure 1. A dissemination of maculopapular rash

palpable examination the lesion was non-painful, pinkred with increased consistency and warmth. After ca. 2 days a spontaneous regression of the infiltration was observed. The presented clinical symptoms were observed for a period of several to a few dozen minutes after each drug administration and persisted for a few hours, then they subsided completely for the next 3 months of Humira treatment, with no concurrent general symptoms. It was decided to simultaneously admin ister Humira, dexamethasone $4 \mathrm{mg} I \mathrm{M}$ and antazoline $100 \mathrm{mg} / 2 \mathrm{ml}$. In this management scheme a reaction, in the form of an infiltration, occurred 30 min after the injection, yet the lesion was significantly smaller in size and it was not accompanied by pruritus. The infiltration regressed significantly faster, being reduced to the period of merely $3 \mathrm{~h}$. The drug management was similar in the period of the following 3 months of drug administration until finally the infiltration ceased to occur. The drug is still being administered to the patient and there has not been observed any local reaction in the drug injection site for 1.5 years.

A 53-year-old male patient was diagnosed with psoriasis vulgaris in 2001. After 11 years the patient started to exhibit symptoms of psoriatic arthritis in the form of tendon sheath inflammation, complained of painful interphalangeal joints of hands and feet as well as complained of painful oedematous tarsal and knee joints. The patient was hospitalized for erythroderma with oedema and shank skin exudates as well as dactylitis within the joints of hands and feet, with concurrent dystrophy of all nail plates. The lesions were accompanied by pain of both knee joints and interphalangeal joints of the feet. Simultaneous administration of methotrexate $25 \mathrm{mg} /$ week and cyclosporine in a dose of $3.5 \mathrm{mg} / \mathrm{kg}$ body weight was included in the treatment. A reduction of skin lesions was observed, yet no PASI score $50 \%$ improvement was recorded. Articular complaints subsided completely. Due to persistent skin lesions the patient was enrolled into the biological treatment program. After administration of the first dose of ustekinumab, the patient experienced strong pain of knee and feet joints which occurred on the second and third day after the

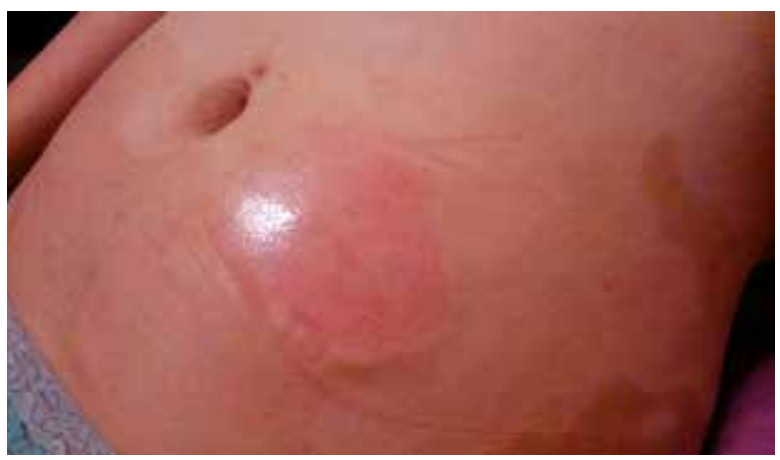

Figure 2. Inflammatory infiltration

drug injection. Additionally, there appeared rachialgia of the lumbar-sacral area, oedema of the shanks and intense general weakness forcing the patient to stay in bed and increased temperature within the limit of $38.5^{\circ} \mathrm{C}$. The patient was unable to work. The above symptoms persisted for a period of 2 weeks after which the patient visited a doctor. The patient was hospitalized for observation and follow-up examinations. Laboratory examinations showed elevated ESR and symptoms of normocytic anaemia. After a period of another 2 weeks the symptoms subsided spontaneously so it was decided to administer the second dose of ustekinumab. The subsequent, pre-planned ustekinumab injections were administered with good drug tolerance, with no occurrence of similar symptoms. Due to prevailing articular complaints the patient has been administered Humira since 2014 with good clinical effect and good tolerance.

The last patient is a 36-year-old female with plaquetype psoriasis diagnosed 20 years ago and psoriatic arthritis diagnosed in 2007. The patient has been complaining of pain intensification in knee and elbow joints for 5 years which was accompanied by oedema and increased warmth. Moreover, interphalangeal joints of the hands and the left foot were affected with formation of the so-called sausage-shaped fingers (dactylitis). Periodically there co-occurred pain and stiffness of the neck region of the spine. The patient was treated with acitretin in a dose of $0.6 \mathrm{mg} / \mathrm{kg}$ body weight and methotrexate $15 \mathrm{mg} /$ week, yet none of the administered treatment 


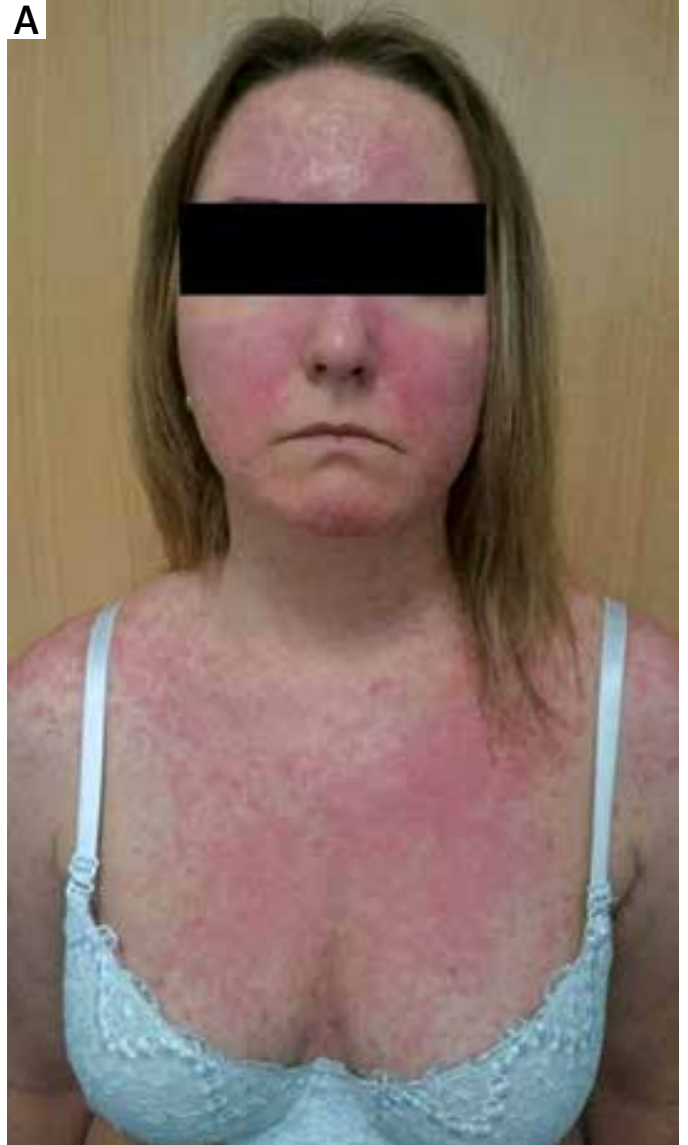

methods brought improvement in PASI 50\% score. Articular complaints and intensification of psoriatic skin lesions (PASI 21.8, DLQI 27 pts, BSA 27.5\%) induced enrolment of the patient into the biological therapy program. The program was started with etanercept (Enbrel) administration. After 2 weeks of treatment there occurred intensified erythema located in the area of the arms, accompanied by warmth of the affected areas, which did not cause any subjective complaints (lack of photographic documentation). The patient was administered antihistamines orally and glucocorticoid creams for external use which resulted in complete subsistence of skin lesions. After a 1-week gap in etanercept administration the treatment was resumed and continued for a period of 18 months.

After Enbrel therapy completion, psoriatic skin symptoms were of the leading nature whereas joint complaints were reduced. Because of that the patient was enrolled into the severe plaque-type psoriasis adalimumab treatment program. Eleven days after the drug administration there occurred a dissemination of exudative-oedematous lesions located on the area of cleavage, arms, back and lower extremities (Figures 3 A, B), which tended to fuse over time. There appeared wheals on the patient's thighs characterized by significant oedema and increased consistency. The patient also complained of se-

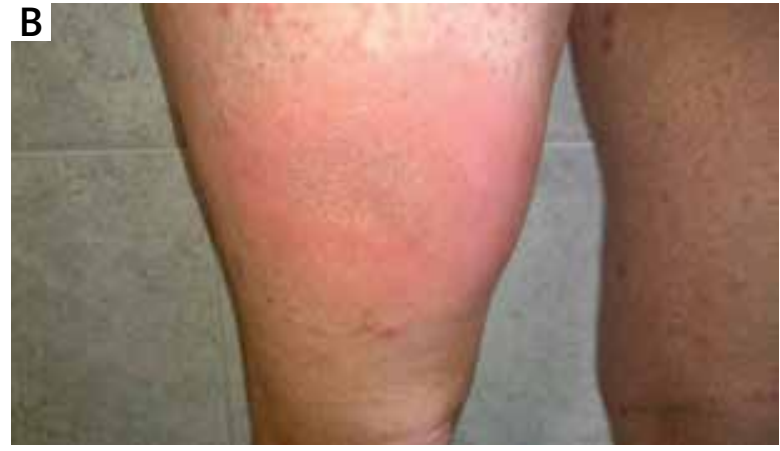

Figure 3. A dissemination of exudative-oedematosus lessions

vere pruritus. It was decided to admit the patient to the Clinical Department of Internal Diseases, Dermatology and Allergology, Specialist Hospital in Zabrze where she was intramuscularly administered antihistamines and dexamethasone $8 \mathrm{mg} /$ day and hydrocortisone locally. Adalimumab treatment was also discontinued. After the administered treatment, a quick and complete remission of the skin lesions was achieved. Adalimumab treatment was resumed after 2 weeks, this time without occurrence of any adverse reactions.

In October of 2015, during Humira treatment in the same patient, there appeared erythematous lesions with stratified soft yellow crusts without any blisters in the chin skin area. Initially the patient was diagnosed with contagious impetigo and fusidic acid was externally administered. Following the treatment administered there was no remission of the lesions observed, instead the lesions gradually assumed the form of maroon-red infiltration with a small amount of squama (Figure 4). The lesions were accompanied by the sensation of skin tension and tightening.

Metronidazole, mometasone and emollients were administered in the following months. This treatment produced no improvement in the patient's condition. Instead, there was observed a constant small increase in the affected chin skin area and occurrence of lesions

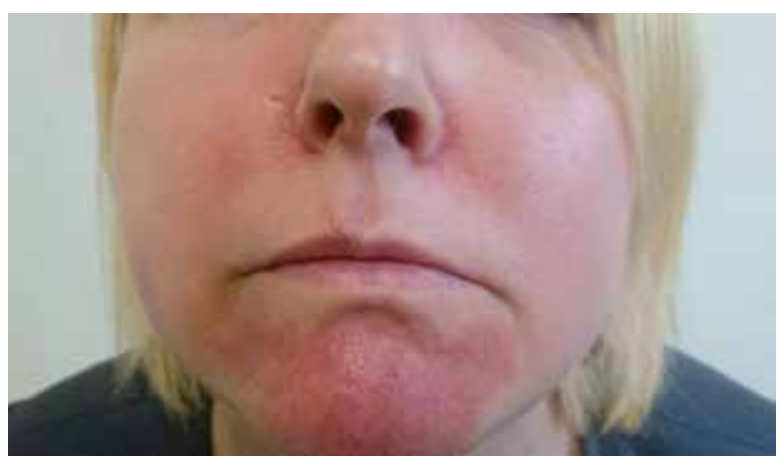

Figure 4. Erythematosus infiltration 
localized in the region of nasolabial grooves in the nasal alar area with evident exacerbation after exposure to UV radiation. In June and September 2016, diagnostic tests were performed for systemic lupus erythematosus and the presence of cytoplasmic homogeneous pattern ANA2 antinuclear antibodies at the titre of $1: 160$ was determined. The ANA3 profile demonstrated presence of native SS-A antibodies (+). After 6 months, ANA titre increased to $1: 320$. In the period between 2011 and 2014 several tests for ANA levels were performed with each test producing a negative result (the presence of granular ANA pattern at the titre of $1: 100$ and cytoplasmic ANA pattern). An unaffected segment of the skin exposed to UV radiation was also collected. IgM-class immunoglobulin deposits (LBT-Lupus Band Test ++ ) were detected in the examined material, at the dermis-epidermis border. The patient is being observed for systemic lupus erythematosus. The patient is currently not administered any biological treatment. Three months after adalimumab discontinuation a clear improvement of the local condition was observed: pallor of the lupus erythematosus and flattening of the infiltration localized on the chin skin and nasolabial grooves.

\section{Discussion}

Despite achieving satisfactory results, biological drug therapy is not free of adverse reactions. Based on the drug safety analyses, the most frequent adverse reactions, occurring in $20 \%$ of the patients, included upper respiratory tract infections, elevated triglyceride levels and cardiovascular episodes [7, 8]. During adalimumab treatment the occurrence of skin complications was observed, such as infiltrative-inflammatory lesions [9], pruritus, abscess [7], as well as deterioration of psoriasis and pain intensification in affected joints $[9,10]$. Similar adverse reactions after administering the first ustekinumab dose were reported by one of the observed patients: general weakness, excessive sweating, oedema of shanks, fever, intensification of skin and articular complaints. Such symptoms did not recur after administering successive drug doses and switching the drug to adalimumab. The cases described in this paper present patients who experienced the occurrence of inflammatory infiltration and pain sensation in the drug administration site as well as dissemination of wheals as the first adverse reaction. The lesions were frequently accompanied by pruritus. The inflammatory infiltration at the drug injection site was reported in long-term observations [9-13]. Similar comments were made by Leonardi et al. [12] who observed hypersensitivity reactions, predominantly urticaria, in patients who were administered adalimumab.

Two of the described patients experienced erythema multiforme type of skin lesions. Mounach et al. [14] described the occurrence of Stevens-Johnson syndrome in a 53-year-old female patient during adalimumab therapy due to rheumatoid arthritis. The symptoms occurred after administration of the fifth dose of the drug. The drug administration was discontinued due to occurrence of lesions localized on mucous membranes. Other authors reported cases of erythema nodosum, also of a recurrent nature [7].

The equally frequently reported adverse reactions occurring after biological drug administration include occurrence or intensification of contagious diseases and opportunistic infections [13]. Bergler-Czop et al. [15] describe occurrence of zoster during adalimumab therapy whereas Justice et al. [16] present disseminated cutaneous herpes simplex virus after infliximab treatment.

A female patient, who simultaneously experienced several different adverse reactions, was of particular interest. She experienced a hypersensitivity reaction in the form of acute urticaria as well as symptoms of erythema multiforme. During adalimumab therapy, as in the case described by Sobjanek et al. [17], the patient demonstrated positive ANA titre and positive Lupus Band Test (++). There also appeared symptoms suggesting the occurrence of drug-induced lupus. Facial skin lesions and hypersensitivity to UV radiation, as well as positive negative immunological test results are related to the received drug, with no prior history of lupus occurrence, indicate a drug-induced lupus diagnosis. One cannot completely exclude the occurrence of idiopathic lupus, yet improvement of the local condition after drug discontinuation indicates drug-induced symptoms. Also Burmester et al. [13] describe the occurrence of a lupus-like syndrome during biological drug therapy. Furthermore, there can be found numerous reports in the literature on the subject concerning cases of lupus erythematosus being induced by anti-TNF- $\alpha$ drugs, including reports of 130 such cases [17-20] that can be found in articles in the English language. Mattozzi et al. [21] present another example of an induced autoimmune disease. The case concerned the occurrence of circumscribed scleroderma during adalimumab treatment. Similar observations are presented by Posada et al. [22] who, while using adalimumab in treatment of a female patient with a Crohn's disease, observed vitiligo foci.

In medical literature there can also be found cases of psoriasis dissemination and psoriasis-like lesions in the course of biological treatment for indications other than psoriasis [1, 2]. Iborra et al. [23] describe such complications after administration of infliximab and adalimumab in the treatment of Crohn's disease. The authors of another interesting article describe 5 patients who experienced the occurrence of plaque psoriasis for the first time during biological therapy [24]. Rallis et al. [25] describe the case of disseminated pustular psoriasis. The mechanism of this phenomenon is probably associated with possible cutaneous interferon $\alpha$ (IFN- $\alpha$ ) induction which predisposes to development of lesions [15]. Within TNF- $\alpha$ inhibitors, infliximab is the drug which most fre- 
quently induces psoriatic eruptions and psoriasis-like ones [26].

Several authors describe patients with alopecia induced by biological drugs. Le Bidre et al. [27] describe patients treated with adalimumab, diagnosed with alopecia areata. Other authors describe diffuse alopecia as a result of TNF- $\alpha$ action [28]. In patients described by Doyle et al. [29] apart from alopecia areata and diffuse alopecia there also occurred psoriasis-like skin lesions. Literature on the subject also describes dermatologic diseases as biological treatment complications, inter alia lichen planus and lichen-like exanthema [30], skin and mucus membrane neoplasms [3] including malignant melanoma [31].

Furthermore, the authors of numerous publications have observed the occurrence of other extra-cutaneous complications which followed administration of biological drugs, such as inflammation of nasal and pharyngeal mucous membrane [31], subacute thyroiditis [11], demyelinating diseases [32], congestive heart failure [13], severe dilated cardiomyopathy [33], purpura of Henoch-Schönlein [34] or pulmonary lymph node tuberculosis [20].

\section{Conclusions}

Despite spectacular, relatively quickly-achieved treatment effects and treatment safety, the action of biological drugs is not free of adverse reactions. Biological drugs used in dermatology do not fulfil all hopes placed in them, yet they are a strong alternative to the hitherto used systemic treatment. There have been observed treatment-related adverse reactions in each of the presented cases. However, they have not posed a considerable threat to patients' lives and the health benefits achieved by the patients have been much more significant.

\section{Conflict of interest}

The authors declare no conflict of interest.

\section{References}

1. Grochowiec M, Pakla-Misiur A, Narbutt J. "Adherence" and "compliance" in the treatment of psoriasis - literature review. Dermatol Rev 2016; 103: 153-61.

2. Tyc-Zdrojewska E, Kaszuba A, Michalak I. Preparaty biologiczne w terapii łuszczycy - doświadczenia własne. Forum Med Rodz 2009; 3: 468-79.

3. Adamski Z. Quo vadis leczenie biologiczne w łuszczycy? Dermatol Rev 2016; 103: 447.

4. Komorowska O, Szczerkowska-Dobosz A, Purzycka-Bohdan D, et al. Łuszczyca jako czynnik ryzyka rozwoju chorób serca i naczyń. Dermatol Rev 2014; 101: 500-6.

5. Miękoś-Zydek B, Ryglewska-Cho A, Lassota-Falczewska M, et al. Jakość życia pacjentów z łuszczycą. Adv Dermatol Allergol 2006; 23: 273-7.
6. Neneman A, Adamski Z. Aspekty kliniczne i epidemiologiczne zaburzeń ogólnoustrojowych u chorych na łuszczycę. Forum Med Rodz 2009; 3: 447-53 .

7. Parcheta P, Kłujszo E. Nawrotowy rumień guzowaty i gruźlica węzłów chłonnych płuc u pacjentki leczonej inhibitorami TNF. Dermatol Rev 2014; 101: 390-6.

8. Asahina A, Ohtsuki M, Etoh T, et al. Adalimumab treatment optimization for psoriasis: Results of a long-term phase $2 / 3$ Japanese study. J Dermatol 2015; 42: 1042-53.

9. Menter A, Thaci D, Papp KA, et al. Five-year analysis from the ESPRIT 10-years postmarketing surveillance registry of adalimumab treatment for moderate to severe psoriaris. J Am Acad Dermatol 2015; 73: 410-9.e6.

10. Nowa B, Sokolik R. Ocena skuteczności i bezpieczeństwa stosowania adalimumabu w leczeniu chorych reumatoidalne zapalenie stawów. Prz Reumatol 2007; 45: 241-7.

11. Chiriac A, Foia L, Chiriac AE, et al. A case of subcute thyroiditis in a patient on adalimumab for treatment of refractory palmo-plantar psoraris. Muller J Sci Res 2014: 5: 70-3.

12. Leonardi C, Papp K, Strober B, et al. The long-term safety of adalimumab treatment in moderate to severe psoriasis: a comprehensive analysis of all adalimumab exposure in all clinical trials. Am J Clin Dermatol 2011; 12: 321-37.

13. Burmester GR, Panaccione R, Gordon KB, et al. Adalimumab: long-term safety in 23458 patients from global clinical trials in rheumatoid arthritis, juvenile idiopathic arthritis, ankylosing spondylitis, psoriatic arthritis, psoriasis and Crohn's disease. Ann Rheum Dis 2013; 72: 517-24.

14. Mounach A, Rezqi A, Nouijai A, et al. Stevens-Johnson syndrome complicating adalimumab therapy in rheumatoid arthritis disease. Rheumatol Int 2013; 33: 1351-3.

15. Bergler-Czop B, Wcisło-Dziadecka D, Wodok K, BrzezińskaWcisło L. Łojotokowe zapalenie skóry oraz infekcja Herpes zoster w trakcie terapii adalimumabem ze wskazań gastroenterologicznych - opis przypadku. Łuszczyca News 2013; 3.

16. Justice EA, Khan SY, Logan S, Jobanputra P. Disseminated cutaneous Herpes Simplex Virus-1 in a woman with rheumatoid arthritis receiving infliximab: a case report. J Med Case Rep 2008; 2: 282.

17. Sobjanek M, Wilkowska A. Anti TNF-alfa induced lupus erythematosus in a patient with psoriasis - diagnostic controversy. Dermatol Rev 2012, 99, 605-10.

18. Katz U, Zandman-Goddard G. Drug-induced lupus: update. Autoimm Rev 2010; 10: 46-50.

19. Vedove CD, Del Giglio M, Schena D, Girolomoni G. Drug-induced lupus erythematosus. Arch Dermatol Res 2009; 301: 99-105.

20. Levine D, Switlyk S, Gottlieb A. Cutaneous lupus erythematosus and anti-TNF-alpha therapy: a case report with review of the literature. J Drugs Dermatol 2010; 9: 83-87.

21. Mattozzi C, Richetta AG, Cantisani C, et al. Morphea, an unusual side effect of anti-TNF-alpha treatment. Eur I Dermatol 2010; 20: 400-1.

22. Posada C, Florez A, Batalla A, et al. Vitiligo during treatment of Crohn's disease with adalimumab, adverse effect of cooccurrence. Case Rep Dermatol 2011; 3: 28-31.

23. Iborra M, Beltrán B, Bastida G, et al. Infliximab and adalimumab-induced psoriasis in Crohn's disease: a paradoxical side effect. J Crohns Colitis 2011; 5: 157-61.

24. Sfikakis PP, Iliopoulos A, Elezoglou A. Psoriasis induced by anti-tumor necrosis factor therapy: a paradoxical adverse reaction, Arthritis Rheum 2005; 52: 2513-8.

25. Rallis E, Korfitis C, Stavropoulou E, et al. Onset of palmoplantar pustular psoriasis while on adalimumab for psoriatic 
arthritis: a 'class effect' of TNF-alpha antagonists or simply an anti-psoriatic treatment adverse reaction? J Dermatolog Treat 2010; 21: 3-5.

26. Ko JM, Gottlieb AB, Kerbleski JF, et al. Induction and exacerbation of psoriasis with TNF-blockade therapy: a review and analysis of 127 cases. J Dermatolog Treat 2009; 20: 100-8.

27. Le Bidre E, Chaby G, Martin L, et al. Alopecia areata during anti-TNF alpha therapy: nine cases. Ann Dermatol Venereol 2011; 138: 285-93.

28. El Shabrawi-Caelen L, La Placa M, Vincenzi C, et al. Adalimumab-induced psoriasis of the scalp with diffuse alopecia: a severe potentially irreversible cutaneous side effect of TNF-alpha blockers. Inflamm Bowel Dis 2010; 16: 182-3.

29. Doyle LA, Sperling LC, Baksh S, et al. Psoriatic alopecia/alopecia areata-like reactions secondary to anti-tumor necrosis factor-alpha therapy: a novel cause of noncicatricial alopecia. Am J Dermatopathol 2011; 33: 161-6.

30. Asarch A, Gottlieb AB, Lee J, et al. Lichen planus-like eruptions: an emerging side effect of tumor necrosis factor-alpha antagonists. J Am Acad Dermatol 2009; 61: 104-11.

31. Manganoni AM, Zane C, Pavoni L, et al. Cutaneous melanoma in patients in treatment with biological therapy: review of the literature and case report. Dermatol Online J 2011; 17: 12 .

32. Asahina A, Ohtsuki M, Etoh T, et al. Adalimumab treatment optimization for psoriasis: results of a long-term phase $2 / 3$ Japanese study. J Dermatol 2015; 42: 1042-52.

33. Burmester G, Mease P, Dijkmans B, et al. Adalimumab safety and mortality rates from global clinical trials of six immunemediated inflammatory diseases. Ann Rheum Dis 2009; 68: 1863-9.

34. Marques I, Lagos A, Reis J, et al. Reversible Henoch-Schönlein purpura complicating adalimumab therapy. J Crohns Colitis 2012; 6: 796-9. 